\title{
Realização e acompanhamento de dois trechos experimentais com asfalto-borracha no estado do Ceará
}

\author{
Jorge Henrique Magalhães Pinheiro e Jorge Barbosa Soares \\ Universidade Federal do Ceará, Brasil
}

\begin{abstract}
RESUMO: Seguindo uma política de desenvolvimento e aprimoramento de novas tecnologias de pavimentação para o estado do Ceará, a Universidade Federal do Ceará realizou, em parceria com os departamentos de transportes locais e a Petrobrás, dois trechos com ligante asfalto-borracha (AB). Além de ecologicamente corretas, misturas com $\mathrm{AB}$ vêm se mostrando eficientes na minimização dos principais defeitos encontrados nos pavimentos flexíveis, deformação permanente e trincamento por fadiga. $O$ presente trabalho traz um estudo da aplicação do ligante $A B$, do controle feito durante a usinagem e compactação, bem como o acompanhamento dos trechos através de medidas de deflexão e de algumas propriedades mecânicas do revestimento antes e após execução. Para a mistura de projeto foram usados agregados graníticos locais e $\mathrm{CaCO}_{3}$ como material de enchimento em uma mistura descontínua tendo como granulometria a faixa do Concreto Asfáltico com Borracha do tipo $\mathrm{G}$ da Califórnia. O ligante asfalto-borracha usado foi produzido pela BR Distribuidora contendo 20\% de borracha e tendo como ligante de origem o CAP 50/60 produzido pela Lubnor e oriundo do petróleo Fazenda Alegre.
\end{abstract}

ABSTRACT: The Federal University of Ceará teamed with local Transportation Department and Petrobrás to construct two trial sections using asphalt-rubber (AR). More than ecologically correct, helping to solve the problem of tire disposal, mixtures with AR have demonstrated improvements in the performance of the pavement, decreasing the main defects of flexible pavements, like rutting and fatigue cracks. For these two sections a quality control requirements were monitored before, during and after the construction. The Benkelman Beam was used for deflection measurements and some mechanical properties were also investigated. Local aggregates were used in a gap graded gradation (type $\mathrm{G}$ of California) and the $\mathrm{CaCO}_{3}$ were used as filler. The AR used was produced by BR Distribuidora with $20 \%$ rubber content.

\section{INTRODUÇÃO}

Desde 1995, a Universidade Federal do Ceará, UFC, vem buscando parcerias junto ao meio acadêmico e aos órgãos rodoviários locais e nacionais com o objetivo de desenvolver e aprimorar novas tecnologias para o setor de pavimentação no estado do Ceará. Naquele ano foi realizado o primeiro trecho experimental do estado (Soares et al., 1999), testando a utilização de um ligante mais viscoso, CAP 30/45, que, segundo as especificações Superpave do SHRP (SHRP, 1994; Motta et al., 1996), seria mais adequado para regiões com o clima local, quente e úmido. Prosseguindo com esta política e visando também dar uma solução ecologicamente correta para os pneumáticos inservíveis, foram executados dois trechos experimentais com asfalto-borracha, $20 \%$ de borracha em um ligante base de CAP 50/60, usando uma mistura descontínua de tamanho máximo nominal de $19 \mathrm{~mm}$.

Com o passar dos anos, os veículos foram transportando cargas mais pesadas e trafegando com pressões maiores nos pneus, contribuindo para degradação precoce dos pavimentos. Devido a tal problema, viu-se a possibilidade de melhorar os revestimentos asfálticos com a adição de polímeros ao ligante (Lewandowski, 1994; Leite, 1999; Oda, 2000). Sendo assim, há mais de 40 anos, os Estados Unidos e vários países da Europa vêm adicionando borracha moída de pneu em ligantes asfálticos, buscando misturas asfálticas mais flexíveis, com maior resistência ao envelhecimento e menor susceptibilidade térmica, trazendo melhores condições de rolamento durante a vida de serviço do pavimento. No Arizona, Estados Unidos, a produção de revestimentos com AB pularam de 900 ton/ano em 1985 para 37.000 ton/ano em 2001 (Way, 2003). A França começou a utilizar ligantes asfalto-borracha (bitume-caoutchouc) em 1982 e, em seis anos, mais de $3.000 .000 \mathrm{~m}^{2}$ foram aplicados em diferentes tipos de revestimentos, de auto-estrada a pistas de aeroportos (Sainton, 1990).

Esta técnica consiste da incorporação de borracha moída de pneu no cimento asfáltico em condições controladas de temperatura, tempo, velocidade de rotação do misturador, granulometria e tipo da borracha, etc (Billiter, 1996; Oda, 2000; Faxina, 2002; 
Fantó, 2003; Specht, 2004). Durante a evolução e o aperfeiçoamento da tecnologia do $\mathrm{AB}$, foram testados vários tipos de misturas, procurando adequações entre a faixa granulométrica dos agregados e a viscosidade do ligante modificado, que é bem superior à do CAP convencional. Misturas densas com asfalto-borracha são efetuadas nos estados da Califórnia e da Flórida, enquanto que o estado do Arizona só emprega misturas de asfalto-borracha abertas e descontínuas. $\mathrm{Na}$ Califórnia, as misturas densas empregam ligante com maior teor de borracha, da ordem de 17 a 23\%, e com viscosidade do ligante asfalto-borracha entre 1.500 a $3.000 \mathrm{cP}$ a $175{ }^{\circ} \mathrm{C}$. Na Flórida as misturas densas são constituídas de ligantes com 6 a 12\% de borracha e viscosidade inferior a $1.500 \mathrm{cP}$ a $175^{\circ} \mathrm{C}$. Quando se usam misturas descontínuas, o ligante pode conter um teor maior de borracha, o que leva a viscosidades mais elevadas (Roberts, 1996; Hicks, 2000; Way, 2003).

Com a recente resolução $n^{\circ} 258$ do Conselho Nacional do Meio Ambiente, CONAMA, todo fabricante de pneus e importador terá que reciclá-los em proporções pré-determinadas, atingindo a proporção máxima em 2005, quando o percentual de reciclagem será de 5 pneus para cada 4 produzidos, o que contribuirá para a diminuição do passivo ambiental de mais de 100 milhões de pneus (Bressan, 2003). Esta legislação, que vem obrigando os produtores a dar destino aos mais de 46 milhões produzidos todo ano no Brasil, encontrou no meio rodoviário um excelente parceiro para a reciclagem e minimização deste problema ecológico responsável pela proliferação de mosquitos transmissores de doenças.

Este artigo traz um estudo da aplicação e do desempenho dos dois trechos com asfalto-borracha realizado no Ceará pela parceria formada entre o Laboratório de Mecânica dos Pavimentos, LMP/ UFC, a Prefeitura Municipal de Fortaleza, PMF, o Departamento de Estradas, Rodovias e Transportes, DERT, a Petrobras/Lubnor e a BR Distribuidora. Neste constam o projeto de mistura, levantamento antes e após a aplicação e um controle durante a usinagem e execução dos dois trechos.

\section{METODOLOGIA}

Foram escolhidos dois trechos para a aplicação do asfalto-borracha, um municipal (Abolição) e outro estadual (CE-350). As características dos dois trechos seguem na Tabela 1.

Para uma avaliação do desempenho do revestimento com $\mathrm{AB}$ é necessário o conhecimento das camadas sobre as quais ele foi colocado, como também do processo construtivo do pavimento. Neste sentido, foi realizado um levantamento antes da colocação do revestimento com asfalto-borracha, aqui chamado de levantamento zero, um controle durante a usinagem e compactação da mistura e um levantamento após a execução.

A dosagem da mistura, análise dos agregados, obtenção dos parâmetros volumétricos e mecânicos, bem como os levantamentos em campo ficaram a cargo do LMP/UFC, enquanto a caracterização do ligante foi realizada pela BR Distribuidora. As temperaturas de mistura e de compactação foram determinadas pelo produtor do CAPFLEX B e a execução dos trechos foi coordenada pela BR Distribuidora e pelos respectivos órgãos rodoviários e executores contratados.

Tabela 1: Características dos trechos experimentais

\begin{tabular}{|c|c|c|}
\hline Características & Abolição & CE-350 \\
\hline Localização & $\begin{array}{l}\text { Av. Abolição, entre Av. Desembargador } \\
\text { Moreira e Rua Joaquim Nabuco, sentido } \\
\text { leste-oeste }\end{array}$ & $\begin{array}{l}\text { CE-350 entre os municípios } \\
\text { de Itaitinga e Pacatuba } \\
\text { (estaca } 595 \text { a 603) }\end{array}$ \\
\hline Tráfego & Intenso com carros, ônibus e caminhões & Intenso, caminhões carreta \\
\hline Tipo & Via urbana & Estrada estadual \\
\hline Largura & $9 \mathrm{~m}$ (3 faixas) & $\begin{array}{l}8 \mathrm{~m} \text { ( } 6 \mathrm{~m} \text { de faixa e } 2 \mathrm{~m} \text { de } \\
\text { acostamento })\end{array}$ \\
\hline $\begin{array}{l}\text { Base ou revestimento } \\
\text { antigo }\end{array}$ & $\begin{array}{l}\text { Até } 3 \text { revestimentos diferentes }(12 \mathrm{~cm} \text { de } \\
\text { CBUQ e base de paralelepípedo) }\end{array}$ & Solo-brita \\
\hline Extensão & $300 \mathrm{~m}$ & $200 \mathrm{~m}$ \\
\hline Espessura nova* & $3,23 \mathrm{~cm}$ & $5,50 \mathrm{~cm}$ \\
\hline
\end{tabular}

*média dos corpos de prova extraídos 


\section{MATERIAIS}

\subsection{Ligante}

$\mathrm{O}$ asfalto-borracha usado teve como ligante base o CAP 50/60 da Lubnor e a incorporação da borracha foi realizada pela BR Distribuidora em sua unidade GESTALF, Diadema. O ligante resultante, CAPFLEX B, foi enviado de Diadema, São Paulo, a Fortaleza, tendo uma defasagem de 11 dias entre a mistura com a borracha e a execução dos trechos. As propriedades do CAP 50/60 estão na Tabela 2, enquanto algumas propriedades do $\mathrm{AB}$ encontram-se na Tabela 3. Alguns autores (Fantó, 2003; Potgieter, 2003) apontam esta técnica de incorporar a borracha em planta e depois transportar para a obra, chamada de terminal blend, como sendo causadora de alguns problemas como: segregação de borracha, perda de viscosidade, envelhecimento etc.

O CAP de base em questão, ao ser misturado com a borracha, é elevado a altas temperaturas $\left(e . g .200^{\circ} \mathrm{C}\right)$ o que poderia ocasionar o seu craqueamento. Não obstante, em ensaios de TGA, thermogravimetric analysis, o ligante apresentou uma boa estabilidade térmica, com decomposição inicial em $230^{\circ} \mathrm{C}$ (Santos et al., 2002).

\subsection{Agregados}

Os agregados utilizados foram adquiridos na pedreira Itaitinga no município de mesmo nome, sendo estes comumente utilizados para os pavimentos da região e atendem as especificações do Departamento Nacional de Estradas e Rodagens, DNER (atual DNIT), quanto à abrasão, durabilidade e índice de forma (agregado graúdo) e equivalente de areia (agregado miúdo). Usou-se cal, $\mathrm{CaCO}_{3}$, e pó de pedra como material passante na peneira $\# 200$.

\subsection{Mistura de projeto}

Para a escolha da faixa granulométrica foram testados 3 tipos de misturas: (i) Faixa C do DNER, (ii) Arizona e (iii) Califórnia. Após análise, foi dada preferência à faixa da Califórnia por apresentar um melhor comportamento mecânico, quando comparada ao CBUQ e à faixa do Arizona, como pode ser visto na Tabela 4.

A granulometria final da mistura escolhida, bem como a faixa seguida, encontram-se na Figura 1, que também apresenta a granulometria de uma mistura usada em um trecho experimental com AB em Brasí-

Tabela 2: Características do CAP 50/60 (ANP, 1993)

\begin{tabular}{lccc}
\hline Características & Método & Especificação & Valor \\
\hline Penetração (dmm) & ASTM D 5 & 50 a 60 & 57 \\
ECA - \% da penetração original & X 021 & 50 min & 72 \\
ECA - Variação de massa (\%) & ASTM D 1754 & 1,0 max & 0,3 \\
Índice de susceptibilidade térmica & X 018 & $-1,5$ a 1,0 & $-0,9$ \\
Ponto de fulgor $\left({ }^{\circ} \mathrm{C}\right)$ & ASTM D 92 & 235 min & 296 \\
Solubilidade em tricloroetileno $(\%)$ & ASTM D 2042 & 99,5 min & 100 \\
Viscosidade Saybolt Furol à $135^{\circ} \mathrm{C}$ & ASTM E102 & 110 min & $222 \mathrm{SSF}$ \\
Aquecimento à $175^{\circ} \mathrm{C}$ & X 215 & Não espuma & Não espuma \\
\hline
\end{tabular}

Tabela 3: Propriedades do CAPFLEX B

\begin{tabular}{lcc}
\hline Ensaio & Valor & Método \\
\hline Penetração $\left(100 \mathrm{~g}, 25^{\circ} \mathrm{C}, 5 \mathrm{seg}\right)(\mathrm{dmm})$ & 40 & ASTM D 5 \\
Ponto de amolecimento $\left({ }^{\circ} \mathrm{C}\right)$ & 56 & ASTM D 36 \\
Recuperação elástica $(\%)$ & 72,5 & ASTM D 6084 \\
Viscosidade Brookfield (sp 31, 6rpm) (cP) & & \\
@ $135^{\circ} \mathrm{C}$ & 3.224 & ASTM D 4402 \\
@ $150^{\circ} \mathrm{C}$ & 2.335 & ASTM D 4402 \\
@ $175^{\circ} \mathrm{C}$ & 1.910 & ASTM D 4402 \\
\hline
\end{tabular}


lia, realizado pela parceria NOVACAP, UnB, ETEC e BR Distribuidora (BR Distribuidora, 2003).

Tabela 4: Parâmetros mecânicos das misturas testadas

\begin{tabular}{lcc}
\hline Misturas & $\begin{array}{c}\text { Módulo de } \\
\text { Resiliência }(\mathrm{MPa})\end{array}$ & $\begin{array}{c}\text { Resistência à } \\
\text { Tração }(\mathrm{MPa})\end{array}$ \\
\hline CBUQ (Faixa C) & 3.500 & 0,57 \\
Califórnia & 3.500 & 1,00 \\
Arizona & 2.500 & 0,65 \\
\hline
\end{tabular}

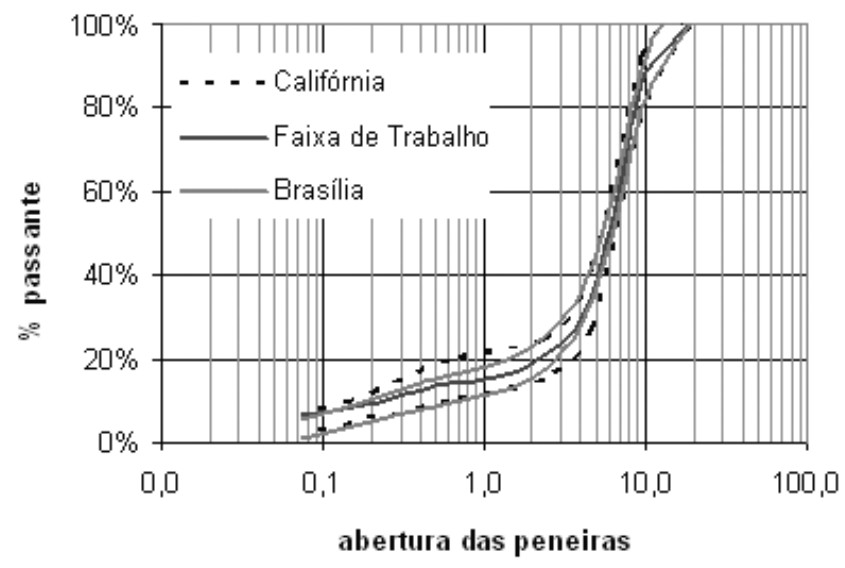

Figura 1: Granulometria da mistura de projeto

\subsubsection{Ajuste durante a usinagem}

Quando da dosagem em laboratório para a determinação do teor ótimo da mistura de projeto, teores de ligante acima de $5,7 \%$ proporcionavam à mistura um aspecto de exsudação (textura brilhosa), conforme pode se ver na Figura 2.

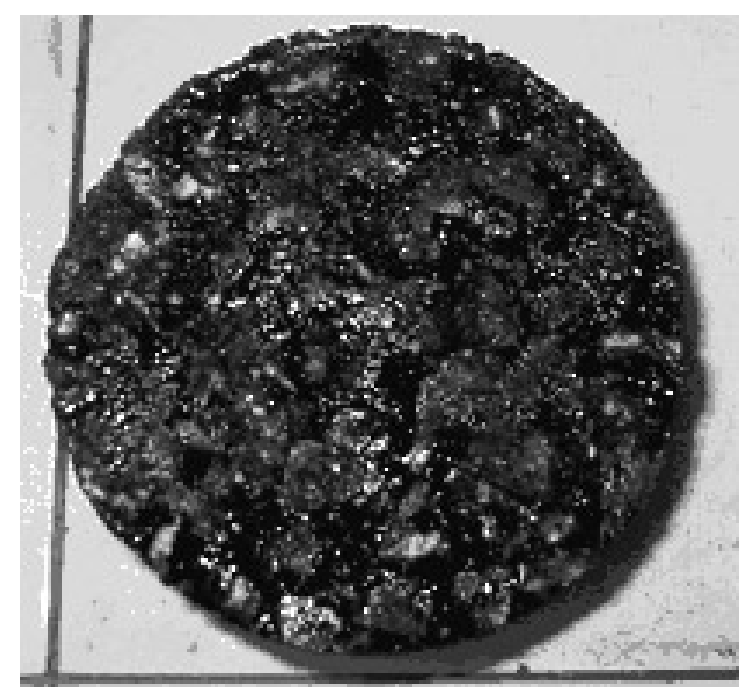

Figura 2: Aspecto exsudado dos corpos de prova
Não obstante, experiências da BR Distribuidora em outros trechos com asfalto-borracha apontam que esta exsudação é apenas aparente e que misturas com $\mathrm{AB}$ têm a capacidade de comportar uma maior quantidade de ligante sem apresentar excesso ou escorrimento em campo. Neste sentido, o teor de ligante de projeto de $5,7 \%$, primeiramente determinado em laboratório, foi ajustado para 7,0\% após uma análise visual durante a usinagem. Após este ajuste, novos corpos de prova foram moldados em laboratório e seus parâmetros mecânicos e volumétricos determinados, como pode ser visto nas Tabelas 5 e 6 . Acredita-se, contudo, que o ajuste adotado esteja magnificado também pelo fato da granulometria dos agregados em campo não ter correspondido com precisão àquela usada em laboratório quando da determinação de teor ótimo de ligante, como será visto mais a frente.

Tabela 5: Parâmetros volumétricos do traço ajustado

\begin{tabular}{lcc}
\hline Parâmetros & Teor de projeto & Teor ajustado \\
\hline Teor de CAP (\%) & 5,7 & 7,0 \\
Densidade aparente & 2,319 & 2,289 \\
Vv (\%) & 4,7 & 4,1 \\
VCB (\%) & 12,7 & 15,6 \\
VAM (\%) & 17,4 & 19,7 \\
RBV (\%) & 73,3 & 79,1 \\
\hline
\end{tabular}

Tabela 6: Parâmetros mecânicos do traço ajustado

\begin{tabular}{lcc}
\hline Parâmetros & Teor de projeto & Teor ajustado \\
\hline $\begin{array}{l}\text { Módulo de resiliência } \\
\text { (MPa) }\end{array}$ & 3.290 & 3.500 \\
$\begin{array}{l}\text { Resistência à tração } \\
(\mathrm{MPa})\end{array}$ & 0,92 & 1,00 \\
\hline
\end{tabular}

\section{LEVANTAMENTO ZERO (ANTES DA EXECUÇÃO)}

Devido à necessidade de se conhecer o pavimento onde foi colocado o revestimento com asfaltoborracha, foram levantadas algumas características dos locais onde se empregou o novo ligante. No caso do trecho que já possuía uma capa asfáltica (Abolição), o levantamento verificou a presença de alguns defeitos localizados, como remendos, trincas longitudinais, trincas isoladas e escorregamento de massa asfáltica em paradas de ônibus. Já para o pavimento novo (CE-350), o levantamento constou de levantamento deflectométrico e de ensaio de re- 
siliência para os materiais de sub-leito, sub-base e base, após a retirada de amostras deformadas destas subcamadas.

\subsection{Parâmetros mecânicos}

Para a determinação das propriedades mecânicas do revestimento existente, foram retirados de 4 corpos de prova em cada ponto de extração. Após a extração dos corpos de prova, foram feitos os ensaios de módulo de resiliência (MR) e resistência à tração (RT). A Tabela 7 traz os valores resultantes de cada ponto de extração, que representam a média dos corpos de prova.

Tabela 7: Parâmetros mecânicos dos corpos de prova da Abolição antes do AB

\begin{tabular}{ccc}
\hline Pontos & MR $(\mathrm{MPa})$ & RT $(\mathrm{MPa})$ \\
\hline 1 & 10.835 & 1,34 \\
2 & 16.193 & 1,08 \\
3 & 14.320 & 1,32 \\
4 & 37.554 & 2,26 \\
5 & 17.550 & 1,80 \\
6 & 13.939 & 1,52 \\
\hline
\end{tabular}

Os valores indicam uma mistura, na verdade um combinado de misturas, bastante rígida, devido ao envelhecimento provocado pela oxidação, que resulta num enrijecimento do material. Vale salientar que a dispersão dos valores aponta uma grande heterogeneidade da mistura, encontrada devido aos diferentes serviços de recapeamento realizados sobre o pavimento ao longo do tempo.

\subsection{Bacias deflectométricas}

As bacias de deflexão, com seus respectivos valores máximos, são mostradas nas Figuras 3 e Figura 4. Vale salientar que o levantamento da bacia para o trecho CE-350 foi realizado sobre a camada de base, já que este ainda não possuía revestimento.

\section{CONTROLE DURANTE EXECUÇÃO}

O trecho Abolição foi realizado no dia 23 de setembro, enquanto o trecho CE-350 foi executado no dia 24 de setembro, ambos em condições climáticas normais e sem chuva. Durante a usinagem e a execução dos trechos experimentais foi realizado um controle de todo material produzido pela usina, permitindo um monitoramento e análise do desempenho do material após sua aplicação em campo.

\subsection{Usinagem}

A usinagem da mistura com asfalto-borracha foi feita em usina volumétrica, do tipo Drum Mix, e ficou a cargo da empresa Installe, para os dois trechos, e sob a orientação e supervisão da BR Distribuidora e do LMP/UFC. O AB, já na temperatura de usinagem, foi bombeado diretamente do caminhão transportador para o tambor de mistura da usina.

Para o enquadramento da curva de projeto na faixa descontínua da Califórnia, foi necessário coletar materiais de várias pedreiras a fim de se conseguir a combinação de agregados pretendida. As pedreiras da região possuem carência de brita com grande quantidade de material retido entre as peneiras 9,5 e $4,8 \mathrm{~mm}$, e como a faixa descontínua procurada contem pelo menos $50 \%$ do material entre estas peneiras, foi demandada à pedreira uma produção de brita com a granulometria desejada. Como será mostrado mais a frente, a granulometria pedida dos agregados não foi totalmente seguida, ocasionando uma mistura com a curva granulométrica diferente da esperada. Outro problema encontrado devido à escassez de agregados com determinadas granulometrias foi a necessidade de se colocar $5 \%$ de fíler comercial, valor muito alto para as obras de pavimentação usuais.

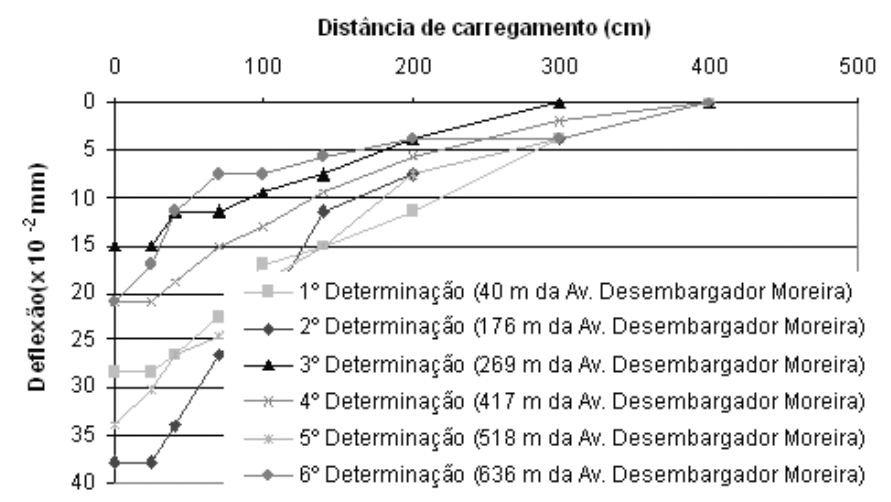

Figura 3: Bacia deflectométrica Abolição

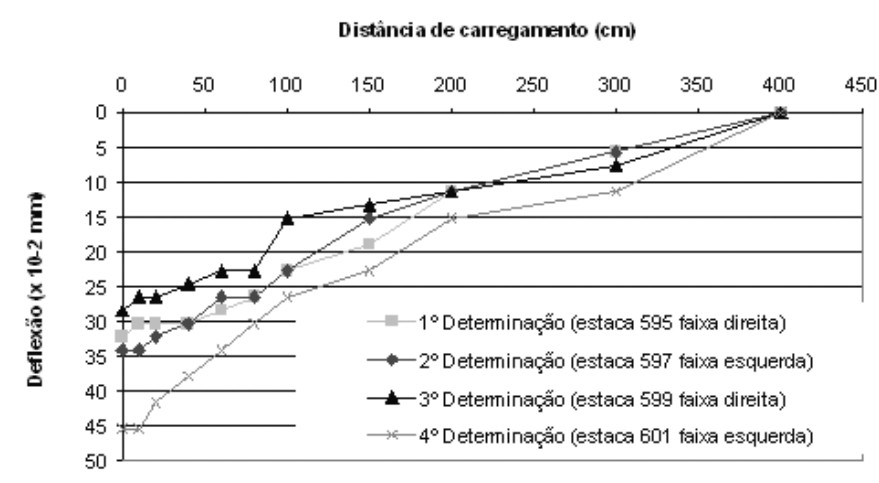

Figura 4: Bacia deflectométrica CE-350 


\subsection{Temperaturas}

Foram medidas as temperaturas do ligante e da massa asfáltica durante o processo de usinagem. A temperatura do ligante, após ajuste inicial, mostrouse estável e sempre acima de $170{ }^{\circ} \mathrm{C}$, como recomendado pelo fabricante. A temperatura da mistura, ao sair da usina, ficou entre $151,4{ }^{\circ} \mathrm{C}$ e $180{ }^{\circ} \mathrm{C}$. O transporte se deu em caminhões basculantes sem o recobrimento por lona, entretanto não foi observada perda significante de temperatura.

\subsection{Teor de ligante}

Para cada caminhão de massa asfáltica que saiu da usina, foram confeccionados em campo 3 corpos de prova, num total de 30 CPs para cada trecho. Os corpos de prova foram moldados em 75 golpes com um compactador Marshall manual. Em laboratório foram determinados os parâmetros volumétricos e mecânicos. Após a determinação destes parâmetros, parte do material foi submetida à extração de ligante pelo método do Rotarex (DNER, 1994a) para a determinação do teor de ligante. Os valores são mostrados na Tabela 8 e representam a média de 7 ensaios para cada trecho. A correção do teor de ligante é devido a separação de parte da borracha do $A B$, fazendo com que esta borracha fique junta dos agregados. O fator de correção de 1,12 foi obtido por experiências do fabricante do CAPFLEX B. Takallou (2003) mostrou que menos de 9\% da borracha permanece com o ligante após extrações.

Apesar do trecho Abolição apresentar um teor médio de $\mathrm{AB}$ de $7,3 \%$, os primeiros $120 \mathrm{~m}$ deste trecho apresentam uma quantidade menor de ligante, tendo em visto ser a parte do trecho, a qual serviu de teste para o ajuste do teor de ligante de projeto, como mencionado anteriormente.

Tabela 8: Teores de ligantes da mistura saída da usina

\begin{tabular}{lcc}
\hline Teores de AB & Abolição & CE-350 \\
\hline Teor (\%) & 6,5 & 6,4 \\
Teor corrigido (\%) & 7,3 & 7,2 \\
\hline
\end{tabular}

\subsection{Granulometria}

Após a remoção do ligante dos corpos de prova, foi realizado o peneiramento do material resultante e determinada a faixa granulométrica. As curvas granulométricas encontradas, tanto para Abolição, como para CE-350, são mostradas na Figura 5.

As granulometrias encontradas divergem bastante da curva de projeto. Apesar desta variação da curva granulométrica poder ser proveniente de uma não representatividade das amostras, acredita-se que todas as precauções necessárias para os ensaios foram tomadas, visando à boa representação da massa usinada. Sendo assim, a alteração da curva granulométrica esperada deveu-se ou por uma imprecisão da usina e ou pela utilização de agregados com as granulometrias diferentes das supostas. Corroborando o que foi dito, estudos vêm mostrando uma baixa precisão de usinas volumétricas, quando comparadas às gravimétricas (USACE, 2000). Há ainda a necessidade de um controle na maneira como os agregados deverão ser colocados nos silos, visando evitar segregação de material.

Vale ressaltar que os agregados ensaiados em laboratório foram coletados diretamente das esteiras do britador em mais de um momento e que a pedreira garantiu a constância da faixa granulométrica produzida pelo equipamento em questão. A conseqüência imediata desta alteração da granulometria da mistura de projeto foi o desenquadramento da faixa descontínua da Califórnia para uma curva contínua enquadrada na Faixa C do DNER, conforme pode ser visto na Figura 5.

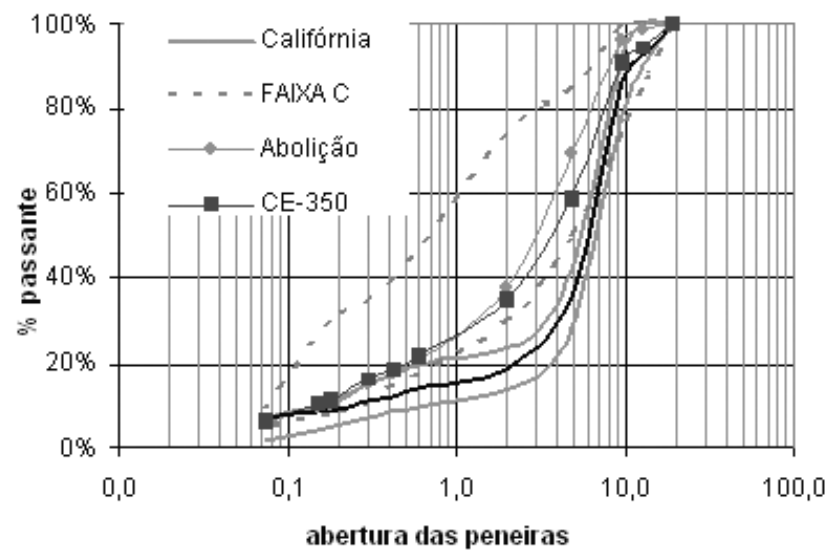

Figura 5: Granulometria de projeto e sua variação durante a usinagem

\subsection{Compactação}

A compactação de ambos os trechos foi realizada por um compactador tandem vibratório de chapa. No início da compactação do trecho Abolição ficou constatada a necessidade de se borrifar óleo diesel e ou água em abundância nos rolos do compactador, já que a massa asfáltica estava aderindo à sua superfície. A falta de experiência em misturas com propriedades diferentes das convencionais, temperaturas de compactação mais elevadas, acarretou um compactação não uniforme e muitas vezes excessiva, com segmentos compactados com maior vibração do que outros, principalmente no início. 
A espessura prevista para ambos os trechos era de $5 \mathrm{~cm}$ após a compactação, no entanto, no trecho Abolição, colocou-se uma espessura de $5 \mathrm{~cm}$ sem compactação, o que resultou em uma espessura compactada de $3,29 \mathrm{~cm}$. Já no trecho de CE-350, a espessura final foi de $5,50 \mathrm{~cm}$.

\subsection{Parâmetros volumétricos}

Antes de serem ensaiados, os corpos de prova tiveram suas densidades aparentes medidas para o cálculo do volume de vazios. A Tabela 9 mostra os resultados.

Tabela 9: Parâmetros volumétricos dos corpos de prova extraídos

\begin{tabular}{lcc}
\hline Parâmetros & Abolição & CE-350 \\
\hline Teor de CAP (\%) & 7,3 & 7,2 \\
Densidade aparente & 2,259 & 2,232 \\
Vv (\%) & 5,0 & 6,3 \\
VCB (\%) & 16,0 & 15,7 \\
VAM (\%) & 21,0 & 21,9 \\
RBV (\%) & 77,2 & 71,4 \\
\hline
\end{tabular}

5.7 Caracterização mecânica dos corpos de prova moldados in loco

Todos os corpos prova moldados durante a usinagem, 30 para Abolição e 30 para CE-350, foram ensaiados e tiveram seus parâmetros mecânicos medidos. A média dos resultados e o desvio padrão encontram-se na Tabela 10.

A grande variação do módulo de resiliência dos corpos de prova do trecho Abolição pode ser devido à diferença dos teores de ligante da massa que saiu da usina, devido ao ajuste inicial do ligante, que variou de 5,7 à $7,0 \%$. Do exposto anteriormente e, quando comparado à Tabela 6 , pode-se notar que apesar da alteração da curva granulométrica da mistura de projeto, houve uma pequena alteração na média dos parâmetros mecânicos esperados em laboratório, embora na se possa perder de vista a grande variação, principalmente do módulo de resiliência na Abolição.

Tabela 10: Parâmetros mecânicos de corpos de prova compactados durante usinagem

\begin{tabular}{lcccc}
\hline \multirow{2}{*}{ Trechos } & \multicolumn{2}{c}{ MR $(\mathrm{MPa})$} & \multicolumn{2}{c}{$\mathrm{RT}(\mathrm{MPa})$} \\
& $\overline{\mathrm{X}}$ & $\mathrm{s}$ & $\overline{\mathrm{x}}$ & $\mathrm{s}$ \\
\hline Abolição & 3.340 & 2.240 & 0,93 & 0,12 \\
CE-350 & 3.120 & 825 & 0,98 & 0,17 \\
\hline
\end{tabular}

\section{LEVANTAMENTO 1 ( 2 MESES APÓS A EXECUÇÃO)}

Nos dias 27 e 28 de novembro foi realizado o primeiro levantamento após a construção dos trechos com asfalto-borracha. O levantamento constou de extração de corpos de prova para ensaios mecânicos e volumétricos e o levantamento das bacias de deflexão.

\subsection{Bacias deflectométricas}

O procedimento usado para o levantamento das bacias de deflexão foi o mesmo utilizado no levantamento zero, usando viga Benkelman (DNER, 1994b). As bacias podem ser vistas nas Figuras 6 e 7, Abolição e CE-350, respectivamente.

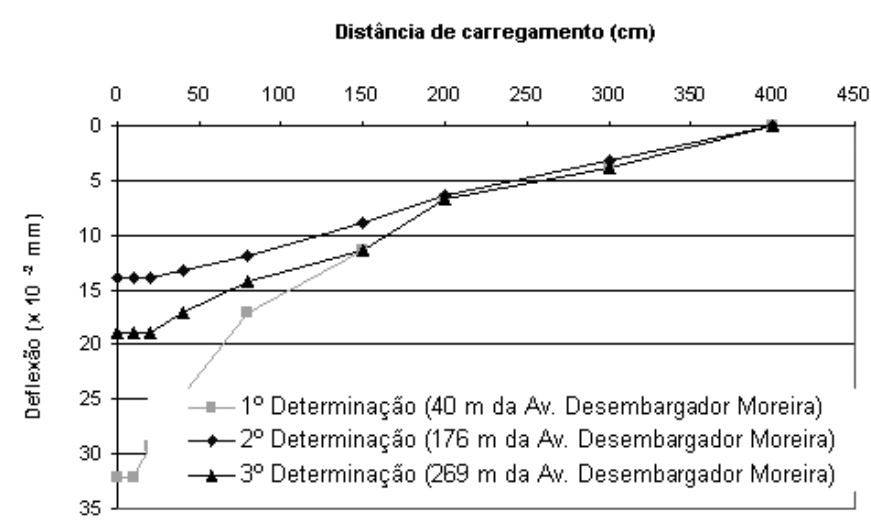

Figura 6: Bacias deflectométricas da Abolição após o asfalto-borracha

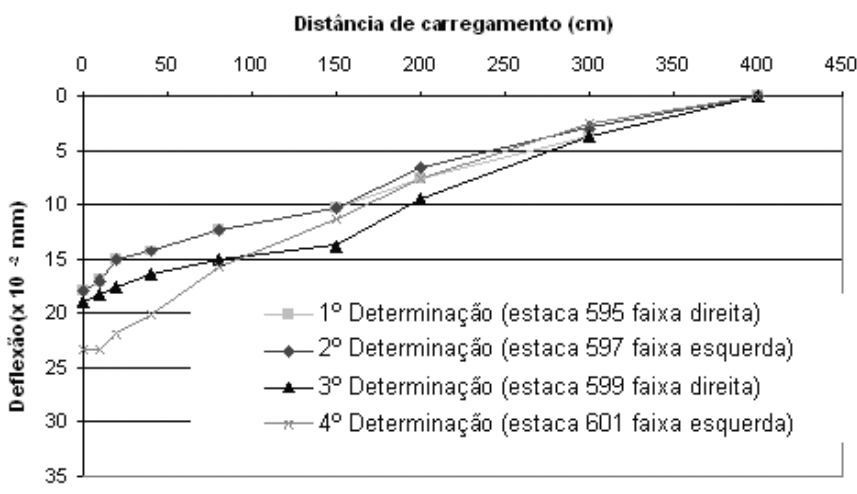

Figura 7: Bacias deflectométricas de Itaitinga após o asfalto-borracha

Ao comparar as bacias de deflexão, antes e após a execução do revestimento com $\mathrm{AB}$, não se verifica uma grande mudança nos valores máximos. Resultado similar foi encontrado em Soares et al. (2000).

\subsection{Parâmetros volumétricos}

Antes de serem ensaiados, os corpos de prova tiveram suas densidades aparentes medidas para o cál- 
culo do volume de vazios em campo. A Tabela 11 mostra os resultados.

Tabela 11: Parâmetros volumétricos dos corpos de prova extraídos

\begin{tabular}{lcc}
\hline Parâmetros & Abolição & CE-350 \\
\hline Teor de CAP (\%) & 7,3 & 7,2 \\
Densidade aparente & 2,290 & 2,220 \\
Vv (\%) & 5,7 & 6,8 \\
VCB (\%) & 15,9 & 15,5 \\
VAM (\%) & 21,6 & 22,3 \\
RBV (\%) & 73,8 & 69,6 \\
\hline
\end{tabular}

\subsection{Parâmetros mecânicos}

Foram realizados ensaios de MR e RT e os valores estão na Tabela 12. Vale salientar, que os corpos de prova extraídos da Abolição tiveram espessuras médias de 3,29 cm e diâmetro médio de $10,50 \mathrm{~cm}$, o que foge das especificações do DNER (DNER, 1994c; DNER, 1994d), que recomendam espessura de 3,50 a 6,50 cm e altura de $10,00 \pm 0,20 \mathrm{~cm}$. Já os corpos de prova da CE-350 tiveram espessura média de $5,50 \mathrm{~cm}$, dentro da norma, e diâmetro médio de $10,50 \mathrm{~cm}$, um pouco acima da norma.

Tabela 12: MR e RT de corpos de prova extraídos

\begin{tabular}{lcccc}
\hline & \multicolumn{2}{c}{ MR $(\mathrm{MPa})$} & \multicolumn{2}{c}{$\mathrm{RT}(\mathrm{MPa})$} \\
Trechos & $\mathrm{x}$ & $\mathrm{s}$ & $\overline{\mathrm{x}}$ & $\mathrm{s}$ \\
\hline Abolição & 5.140 & 1.134 & 0,85 & 0,11 \\
CE-350 & 3.740 & 830 & 0,80 & 0,04 \\
\hline
\end{tabular}

\section{CONSIDERAÇÕES FINAIS}

A realização dos dois trechos experimentais com asfalto-borracha no estado do Ceará trouxe um grande impulso qualitativo para o meio rodoviário envolvido, seja pelo aprendizado com erros e dificuldades encontrados, seja pela colocação em prática do conhecimento previamente estudado. Todo o processo operacional da construção de revestimento com asfalto-borracha evidenciou a necessidade de um planejamento rigoroso e eficaz de todas as etapas, deste à produção do ligante $\mathrm{AB}$ à compactação da mistura. Ficou constatada a grande dificuldade do enquadramento dos agregados produzidos pelas pedreiras locais nas faixas descontínuas, comumente usadas para o ligante AB. Além disso, a realidade local de usinagem mostrou-se deficiente e pouco precisa no controle dos materiais.

A dosagem em laboratório deve ser baseada em parâmetros volumétricos e o problema de exsudação do ligante não deve ser levado em conta, tendo em vista a não observação deste durante execução. Este aspecto de excesso de ligante levou ao ajuste do teor ótimo de ligante durante a usinagem, passando de $5,7 \%$ para $7,0 \%$. A alteração da curva de projeto, devido ao fornecimento de agregados com granulometrias diferentes das esperadas e a baixa precisão da usina, transformou a curva descontínua pretendida a priori em uma curva contínua, provocando mudanças nos parâmetros estudados em laboratório. Comparando os parâmetros volumétricos entre os corpos de provas extraídos do revestimento asfalto-borracha, os confeccionados a partir do material saído diretamente da usina e os moldados no teor e granulometria de projeto, verificou-se misturas com volumes de vazios, Vv, diferentes. Não obstante, as tais misturas apresentaram parâmetros mecânicos parecidos (Tabelas 13 e 14). Acredita-se que a grande diferença do MR dos corpos extraídos da Abolição seja devida à dimensão reduzida dos corpos de prova, com 3,23 cm de espessura.

Tabela 13: Comparação entre as misturas do trecho Abolição

\begin{tabular}{lcccc}
\hline Abolição & MR (MPa) & RT (MPa) & Da & Vv \\
\hline Mistura de projeto & 3.500 & 1,00 & 2,289 & 4,1 \\
Mistura de campo (usina)* & 3.340 & 0,93 & 2,259 & 5,0 \\
Mistura de campo (extração)** & 5.140 & 0,85 & 2,290 & 5,7 \\
\hline
\end{tabular}

* corpos de prova confeccionados com compactador Marshall durante a usinagem

** corpos de prova extraídos dos trechos 
Tabela 14: Comparação entre as misturas do trecho CE-350

\begin{tabular}{lcccc}
\hline CE-350 & MR (MPa) & RT (MPa) & Da & Vv \\
\hline Mistura de projeto & 3.500 & 1,00 & 2,289 & 4,1 \\
Mistura de campo (usina)* & 3.120 & 0,98 & 2,232 & 6,3 \\
Mistura de campo (extração)** $^{*}$ & 3.740 & 0,80 & 2,220 & 6,8 \\
\hline
\end{tabular}

* corpos de prova confeccionados com compactador Marshall durante a usinagem

** corpos de prova extraídos dos trechos

Ainda analisando os parâmetros volumétricos, ficou constatado um maior volume de vazios da mistura extraída de campo, quando comparada a mesma mistura compactada na usina por compactador manual, o que vem a contrariar as expectativas de uma sobrecompactação em campo, devido à passagem excessiva do rolo.

Além de um bom planejamento, com especial atenção à usinagem e à compactação, ser fundamental para a boa execução do revestimento, estudos devem ser feitos no ligante para saber sobre sua estabilidade durante o transporte entre a incorporadora de borracha e a usina, já que trabalhos apontam a perda de propriedades do ligante com incorporações do tipo terminal blend.

\section{REFERÊNCIAS}

Billiter, T.C. (1997) The Characterization of Asphalt-Rubber Binder. Dissertation, Texas A\&M University, College Station, EUA.

BR Distribuidora (2003) Relatório da Aplicação do Asfaltoborracha em um trecho Experimental.

Bressan, S. (2003) Brasil Pode Virar "Lixão" Mundial de Pneus. Informativos OnLine, Biodiversidade. Disponível em: http:// www.anbio.org.br/bio/biodiver inf216.htm - 30/10/ 2003.

DNER (1994a) ME 053 - Misturas Betuminosas - Percentagem de Betume. Departamento Nacional de Estradas de Rodagem, Rio de Janeiro.

DNER (1994b) ME 024 - Pavimento - determinação das deflexões pela viga Benkelman. Departamento Nacional de Estradas de Rodagem, Rio de Janeiro.

DNER (1994c) ME 138 - Misturas Betuminosas - determinação da resistência à tração por compressão diametral. Departamento Nacional de Estradas de Rodagem, Rio de Janeiro.

DNER (1994d) ME 133 - Misturas Betuminosas - determinação do módulo de resiliência. Departamento Nacional de Estradas de Rodagem, Rio de Janeiro.

Fantó, E.; R. Durgó; Sz. Bíró; L. Bartha; Gy. Deák (2003) Effect of Storage Time on Rheological Properties of Crumb Rubber Modified Bitumen. Proceedings of the Asphalt Rubber 2003.

Faxina, A.L. (2002) Estudo em Laboratório do Desempenho de Concreto Asfáltico Usinado a Quente Empregando Ligante
Tipo Asfalto-Borracha. Dissertação de Mestrado, EESC, São Carlos, SP, Brasil.

Hicks, R.J. (2002) Asphalt Rubber Design and Construction Guidelines. Northern Califórnia Rubberized Asphalt Concrete Center (NCRACTC), California Integrated Waste Management Board (CIWMB), Rubber Pavements Association.

Leite, L.M. (1999) Estudo do Preparo e caracterização de asfaltos modificados por polímero. Tese de Doutorado, IMA/ UFRJ, Rio de Janeiro, RJ, Brasil.

Lewandowski L.H. (1994) Polymer Modification of Paving Asphalt Binders. In: Rubber Chemistry and Technology: Polymers in Asphalt.

Motta, L.M.G., Tonial, I., Leite, L.M. e Constantino, R.S. (1996) Princípios do Projeto e Análise SUPERPAVE de Misturas Asfálticas. Tradução comentada, IBP.

Oda, S. (2000) Análise da Viabilidade Técnica da Utilização do Ligante Asfalto-Borracha em Obras de Pavimentação, Tese de Doutorado, EESC, São Carlos, SP, Brasil.

Potgieter, C.J.; J.S. Coetsee (2003) Bitumen Rubber Asphalt. Proceedings of the Asphalt Rubber 2003.

Roberts, F.L.; P.S. Kandhal; R.E. Brown; D. Lee e T.W. Kennedy (1996) Hot Mix Asphalt Materials, Mixture Design, and Construction. NAPA. Maryland.

Sainton, A. (1990) Les Avantages du Liant Bitume-Caoutchouc pour les Enrobés Drainants, Revue Générale des Routes et des Aérodromes, Spécial Printemps, p. 3-9.

Santos, E.F.; G.M. Silva; J.P.A. Feitosa; J.B. Soares (2003) Caracterização de Cimento Asfáltico de Petróleo Brasileiro Modificado por Borracha de Pneu Moído de Renovadoras. $2^{\circ}$ Congresso Brasileiro de P\&D em Petróleo e Gás, Rio de Janeiro.

SHRP (1994) Superior Performing Asphalt Pavements (SUPERPAVE): the Product of SHRP Asphalt Research Program. Strategic Highway Research Program A-410, National Research Council, Washington, DC.

Soares, J.B.; L.M.G. Mota; L.M Leite (1999) Quatro Anos de Observação da Pista Experimental do Ceará. XIII Congresso de Pesquisa e Ensino em Transportes, ANPET, 1999, São Carlos. Anais. 1999. v. I, p.263-272.

Soares, J.B.; L.M.G. Mota; R.F. Leite (2000) Análise de bacias deflectométricas para o controle de construção de pavimentos asfálticos. XIV Congresso de Pesquisa e Ensino em Transportes, ANPET, 2000, Gramado.

Specht, L.P. (2004) Avaliação de Misturas Asfálticas com Incorporação de Borracha Reciclada de Pneus, Tese de Doutorado, UFRGS, Porto Alegre, RS, Brasil. 
Takallou, H.B.; M.B. Takallou (2003) Effects of Mixing Time and Temperature on the Visco-elastic Properties of Asphalt Rubber Binder. Proceedings of the Asphalt Rubber 2003.

USACE (2000) Hot-Mix Asphalt Paving. US Army Corps of Engineers, EUA.
Way, G.B. (2003a) The Rubber Pavements Association, Technical Advisory Board Leading the Way in Asphalt Rubber Research. Proceedings of the Asphalt Rubber 2003.

Way, G.B. (2003b) OGFC Meets CRM Where the Rubber Meets the Rubber 15 Years of Durable Success. Proceedings of the Asphalt Rubber 2003. 